\title{
First evidence of a mamenchisaurid dinosaur from the Upper Jurassic-Lower Cretaceous Phu Kradung Formation of Thailand
}

Suravech Suteethorn, Jean Le Loeuff, Eric Buffetaut, Varavudh Suteethorn, and Kamonrak Wongko Acta Palaeontologica Polonica 58 (3), 2012: 459-469 doi: http://dx.doi.org/10.4202/app.2009.0155

An isolated posterior cervical vertebra of a sauropod discovered at Phu Dan Ma (Kalasin Province, northeastern Thailand) is the first informative postcranial specimen from the Phu Kradung Formation, a Upper Jurassic to Lower Cretaceous continental unit. The vertebra is referred to the family Mamenchisauridae, otherwise mainly known from China. In addition, spatulate teeth from the same formation and a mid-dorsal vertebra from the Upper Jurassic Khlong Min Formation of southern Thailand are reassigned to this family. The occurrence of mamenchisaurids in the earliest Cretaceous of Thailand supports a hypothesis of geographical isolation of Central, Eastern, and Southeast Asia during the Late Jurassic. It also suggests that the main changes in their dinosaur assemblages occurred during the Early Cretaceous, rather than at the Jurassic-Cretaceous boundary.

Key words: Dinosauria, Mamenchisauridae, Jurassic, Cretaceous, Thailand.

Suravech Suteetthorn [suteethorn@yahoo.com], Department of Biology, Faculty of Science, Mahasarakham University, Khamrieng, Kantharawichai, 44150 Maha Sarakham, Thailand; Palaeontological Research and Education Centre, Mahasarakham University, Khamrieng, Kantharawichai, 44150 Maha Sarakham, Thailand; and CNRS, UMR 5554 - cc064, Institut des Sciences de l'Evolution de Montpellier, Université Montpellier 2, Place Eugène Bataillon, 34095 Montpellier Cedex 5, France; Jean Le Loeuff [jean.leloeuff@ dinosauria.org], Musée des Dinosaures, 11260 Espéraza, France; Eric Buffetaut [eric.buffetaut@sfr.fr], CNRS, UMR 8538, Laboratoire de Géologie de l'Ecole Normale Supérieure, 24 rue Lhomond, 75231 Paris Cedex 05, France; Varavudh Suteethorn [suteethorn@ hotmail.com ], Palaeontological Research and Education Centre, Mahasarakham University, Khamrieng, Kantharawichai, 44150 Maha Sarakham, Thailand; Kamonrak Wongko [uree40@yahoo.com], Bureau of Fossil Research and Geological Museums, Department of Mineral Resources, 75/10 Rama 6 Road, 10400 Bangkok, Thailand. 
This is an open-access article distributed under the terms of the Creative Commons

Attribution License (for details please see creativecommons.org), which permits unrestricted use, distribution, and reproduction in any medium, provided the original author and source are credited.

Faril Full text $(645.7 \mathrm{kB})$ 